\title{
Challenges in Implementing Routine Cardiopulmonary Exercise Testing in Cystic Fibrosis Clinical Practice: a Single-Centre Review
}

\author{
Owen William Tomlinson ${ }^{1,2}$ (D) Jayne $\operatorname{Trott}^{1} \cdot$ Craig Anthony Williams $^{1,2}$. \\ Nicholas John Withers ${ }^{1} \cdot$ Patrick John Oades ${ }^{1}$
}

Accepted: 12 February 2020 / Published online: 20 February 2020

(C) The Author(s) 2020

\begin{abstract}
Cardiopulmonary exercise testing (CPET) is viewed by many as the gold standard for assessing exercise capacity in CF, being recommended on an annual basis. However, not all patients undergo CPET for varying reasons. This service evaluation retrospectively reviewed data from 179 (92 male) patients in a single CF centre in the UK to identify such reasons. A total of 75/179 patients underwent CPET, whilst 104/179 did not. Of these 104, 41 patients were $\leq 11$ years of age. Of the remaining 63 patients, 26 did not undergo CPET for clinical reasons including needing IV antibiotics, musculoskeletal issues and obesity. Seventeen refused to undergo CPET because of reasons such as an unwillingness to travel and dislike of CPET. Twenty did not undergo CPET for miscellaneous reasons including difficulty contacting patients. Individuals with $\mathrm{FEV}_{1}<40 \%$ predicted were $85.7 \%$ less likely to undertake a CPET than individuals with $\mathrm{FEV}_{1} \geq 70 \%_{\text {predicted. }}$. Understanding these challenges will assist clinical teams with future implementation of CPET into routine care, by identifying areas for improvement and establishing strategies for enhancing future provision of the test.
\end{abstract}

Keywords Exercise testing $\cdot$ Barriers $\cdot$ Clinical practice $\cdot$ Cystic fibrosis

\section{Introduction}

A high level of aerobic fitness is beneficial to individuals with cystic fibrosis (CF), with an increased level of fitness being associated with a lower risk of mortality [1]. Given the importance of identifying and monitoring aerobic fitness, exercise testing is recommended to take place annually [2]. Cardiopulmonary exercise testing (CPET) is acknowledged

This article is part of the Topical Collection on Medicine

A preliminary abstract associated with this research was presented at the 41 st European Cystic Fibrosis Conference in Belgrade 2018 and was subsequently published within a supplement of the Journal of Cystic Fibrosis under the following citation:

Trott, J., et al. (2018). "P150 Reasons for non-compliance with cardiopulmonary exercise testing in cystic fibrosis". Journal of Cystic Fibrosis, 17, S101.

Owen William Tomlinson

o.w.tomlinson@exeter.ac.uk

1 Royal Devon and Exeter NHS Foundation Trust Hospital, Barrack Road, Exeter EX2 5DW, UK

2 Children's Health and Exercise Research Centre, Sport and Health Sciences, University of Exeter, Heavitree Road, Exeter EX1 2LU, UK as the 'gold standard' methodology in CF [3], with this service having been successfully implemented in some $\mathrm{CF}$ centres in the United Kingdom (UK) [4].

Despite recommendations, many $\mathrm{CF}$ centres within the National Health Service (NHS) of the UK do not perform annual CPETs, instead using alternative 'field'-based exercise tests [5], such as the modified shuttle walk test (MSWT) and six-minute walk test (6MWT). This preference is driven in part by equipment availability [6]. Within CF centres that offer CPET as part of standard care, not all patients will perform CPET, for reasons yet to be fully characterised.

To further develop services and facilitate implementation of CPET nationally in CF centres, identification of challenges faced by staff and patients is warranted. This service evaluation goes some way towards this by providing reasoning as to why some patients do not perform CPET in a combined (adult and paediatric) CF centre in the UK.

\section{Methods}

Annual review data from a single calendar year (2017) for all 179 (92 male) patients with CF under the care of the Royal Devon and Exeter NHS Foundation Trust Hospital CF service 
was retrospectively reviewed and analysed. As this service evaluation (a) used anonymised data and (b) results could not be generalised beyond the CF centre in question, an ethics application was not required as per NHS Health Research Authority guidelines.

Patient data at the time of annual review was collated to provide profiles of individuals who did/did not undertake a CPET, with characteristics provided in Table 1. Whilst a small number of patients will undertake more than one exercise test in a calendar year (e.g. evaluation of therapeutic regimens, research studies), this does not happen for every patient. Therefore, data presented herein is solely related to tests at annual review as this is a time whereby all patients are requested to perform a CPET if possible.

Age at annual review was calculated and decimalised to the nearest 0.1 years. To characterise sex, patients were assigned to 'male' and 'female' groups, based upon biological characteristics at birth. Body mass index (BMI) was split into categories of underweight $(<18.5)$, normal (18.5-24.9), overweight (25.0$29.9)$ and obese $(\geq 30)$ [7]. Forced expiratory volume in one second $\left(\mathrm{FEV}_{1}\right)$ was expressed as a percentage of predicted from GLI equations [8], and split into categories of 'mild' $(\geq 70 \%)$, 'moderate' $(40<70 \%)$ and 'severe' lung disease $(<40 \%)$.

Reasons why patients did not undergo CPET were identified from physiotherapy annual reviews, and split into three broad categories: clinical, refusal and miscellaneous. Clinical and miscellaneous reasons were categorised by clinical staff, and refusals were stated by the patients themselves. Where patients did not undergo CPET (for any reason), participation in alternative field tests of MSWT [9] and 6MWT [10] was also assessed.

All statistical analyses were performed using IBM SPSS v.24 (IBM, Armonk, NY, USA). Chi-squared tests identified associations between uptake of CPET and sex, BMI and $\mathrm{FEV}_{1}$ categories. Logistic regression identified whether sex or categories of BMI or $\mathrm{FEV}_{1}$ predicted likelihood of patients performing CPET, in those eligible for the test. Significance was set at $p<0.05$.

\section{Results}

Annual review data of all 179 patients was successfully reviewed, with patient characteristics provided in Table 1. Within this sample, 138 patients were eligible for CPET. Of the 75 performing CPET, 13/75 did not use on-line gas analysis (62/75 did) due to microbiological contraindications (e.g. non-tuberculous mycobacteria, Burkholderia cepacia). Patient eligibility and uptake of CPET is displayed in Fig. 1.

Of all 179 patients, 41 were deemed too young (all were aged $\leq 11$ years) for CPET, and therefore 21 performed a MSWT instead, completing a mean distance ( \pm standard deviation) of $839 \pm 199 \mathrm{~m}$ (range 350-1080 m). Of the remaining 20 patients $\leq 11$ years who did not perform CPET or MSWT, all were aged $\leq 6$ years. Whilst all patients excluded on the basis of age happened to be aged $\leq 11$ years, five children $\leq 11$ years were still able to undertake a CPET and are therefore included in the 'eligible' sample of $n=138$. Of the 63 eligible patients ( $>12$ years) who did not perform CPET, 17 refused, and a further 26 and 20 did not perform CPET for clinical and miscellaneous reasons, respectively, with specific reasons highlighted in Fig. 2. Of these 63, 27 performed alternative exercise tests: MSWT $=24(767 \pm 341 \mathrm{~m}, 240$ $1410 \mathrm{~m}) ; 6 \mathrm{MWT}=3(413 \pm 214 \mathrm{~m}, 279-660 \mathrm{~m})$. The remaining 36 patients did not perform any exercise test (clinical $=12$, refusal $=10$, miscellaneous $=14$; Fig. 1 ).

Statistically significant associations between uptake of CPET and $\mathrm{FEV}_{1}$ category were identified $(p<0.01)$. A significant logistic regression $(p=0.026)$ identified that individuals who were eligible for CPET (i.e. no patients $\leq 11$ years) with $<40 \%$ predicted were $85.7 \%$ less likely to perform CPET than those with $\mathrm{FEV}_{1} \geq 70 \%$ predicted $(p=0.08, \beta=0.143$, $95 \% \mathrm{CI}=0.034-0.596)$. No significant associations were found between sex and uptake of CPET $(p=0.34)$, nor was sex a significant predictor of performing CPET ( $p=$ 0.26). Categories of BMI approached significance with

Table 1 Characteristics of participants analysed for study

\begin{tabular}{|c|c|c|c|c|c|}
\hline & \multirow[t]{2}{*}{ All patients $(n=179)$} & \multirow[t]{2}{*}{ Eligible patients $(n=138)$} & \multicolumn{2}{|l|}{ CPETs $(n=75)$} & \multirow[t]{2}{*}{ No CPET $(n=63)$} \\
\hline & & & Full gas $(n=62)$ & Non-gas $(n=13)$ & \\
\hline $\mathrm{M} / \mathrm{F}$ & $92 / 87$ & $74 / 64$ & $38 / 24$ & $5 / 8$ & $49 / 55$ \\
\hline Age (years) & $22.6( \pm 15.0)$ & $27.9( \pm 13.1)$ & $26.1( \pm 12.0)$ & $22.2( \pm 7.5)$ & $20.4( \pm 17.0)$ \\
\hline $\mathrm{FEV}_{1}\left(\%_{\text {predicted }}\right)$ & $74.5( \pm 25.0)$ & $72.0( \pm 25.0)$ & $75.9( \pm 23.9)$ & $79.3( \pm 21.2)$ & $72.6( \pm 26.5)$ \\
\hline BMI $\left(\mathrm{kg} \mathrm{m}^{-2}\right)$ & $22.6( \pm 5.4)$ & $23.8( \pm 5.0)$ & $23.6( \pm 3.6)$ & $22.7( \pm 3.4)$ & $21.8( \pm 6.6)$ \\
\hline$\dot{\mathrm{V}} \mathrm{O}_{2 \max }\left(\mathrm{mL} \mathrm{kg}^{-1} \min ^{-1}\right)^{*}$ & - & - & $28.85( \pm 7.49)$ & $\mathrm{n} / \mathrm{a}$ & $\mathrm{n} / \mathrm{a}$ \\
\hline
\end{tabular}

All values are presented as mean ( \pm standard deviation). CPET, cardiopulmonary exercise test; $M$, male; $F$, female; $F E V_{l}$, forced expiratory volume in one second; $B M I$, body mass index; $\dot{V} O_{2 \max }$, maximal oxygen uptake. *Ratio-standard scaling sufficient in removing residual effects of body size, therefore $\mathrm{VO}_{2 \max }$ scaled relative to body mass 
Fig. 1 Flow-chart for lack of uptake of exercise testing in a centre-wide sample of 179 people with cystic fibrosis. 6MWT sixminute walk test, CPET cardiopulmonary exercise test, MSWT modified shuttle walk test

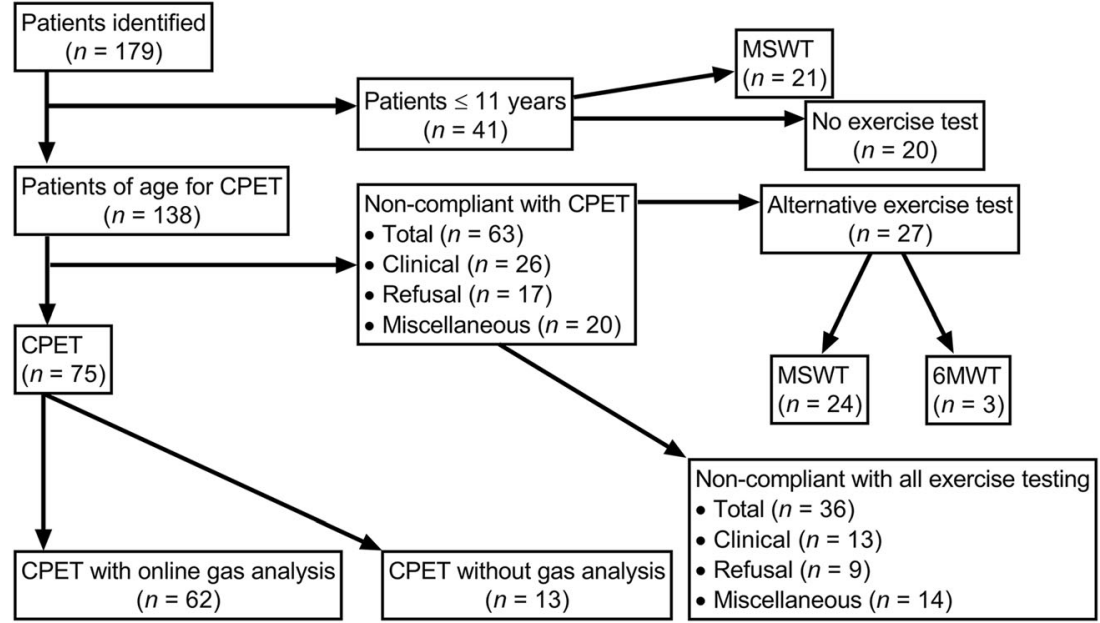

regard to associations $(p=0.052)$ as more individuals who were normal weight and overweight performed a CPET $(n=$ $65)$ versus those who did not $(n=37)$. In contrast, more people who were underweight or obese did not perform CPET $(n=18)$ versus those who did $(n=10)$. With regard to logistic regression, BMI category was not statistically significant $(p=0.07)$, although this model as a whole did approach the statistical threshold value of $p=0.05$. However, when broken down into categories, no significant differences were reported between groups $(p>0.22)$.

\section{Discussion}

This single-centre review identifies multiple reasons as to why people with $\mathrm{CF}$ do not perform CPET, information that can be utilised to further integrate CPET into routine care. Within this cohort, $42 \%$ of all patients performed CPET as part of their annual review process, with this value increasing to $69 \%$ when all forms of exercise testing were considered (CPET, MSWT and 6MWT).
Fig. 2 Reasons for lack of uptake of cardiopulmonary exercise testing in a combined (adult and paediatric) $\mathrm{CF}$ centre. $\mathrm{CF}$ cystic fibrosis, CPET cardiopulmonary exercise test, MDT multidisciplinary team, NTM nontuberculous mycobacteria

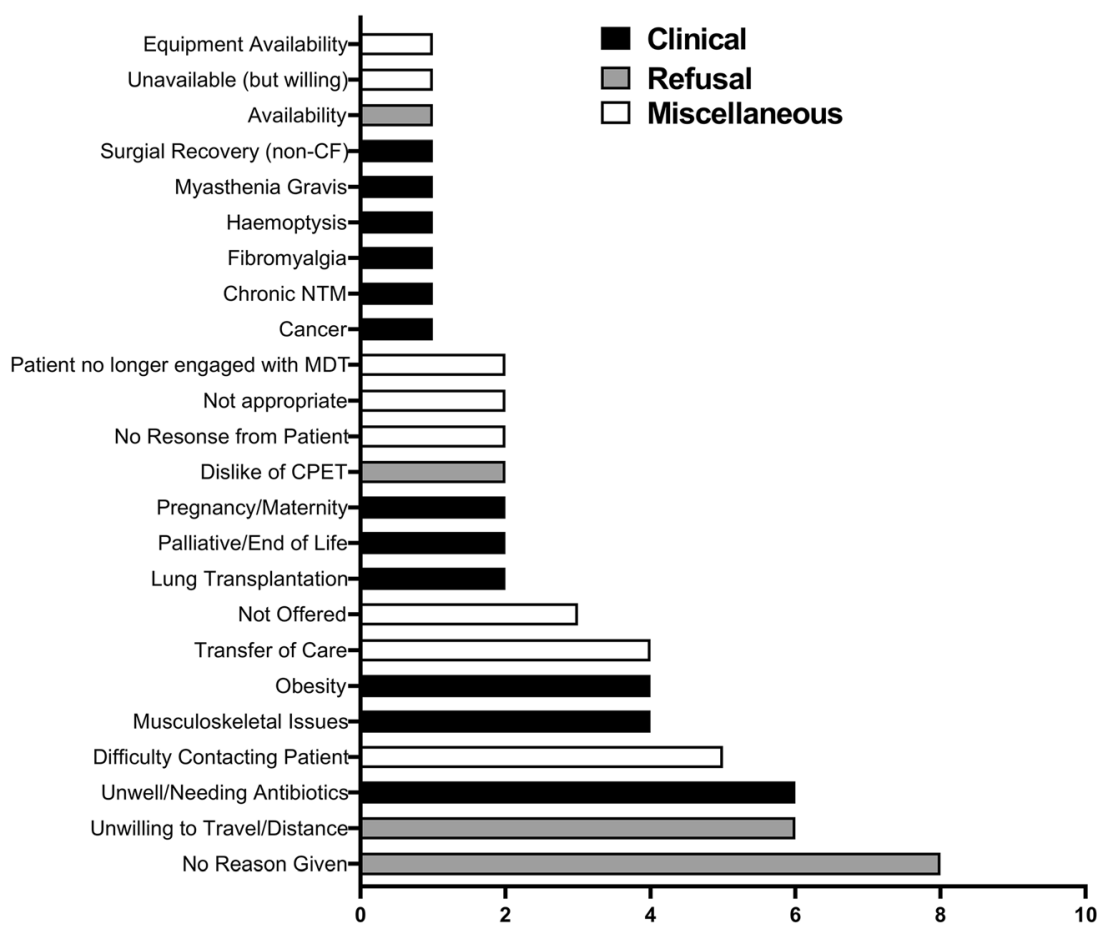

Number of Patients 
However, $18.8 \%$ of eligible patients did not perform CPET for clinical reasons, such as needing intravenous antibiotics, musculoskeletal issues and obesity. These reasons were categorised by clinical staff, and in most instances proved to be complete contraindications to exercise (e.g. haemoptysis), leading to tests not being offered to patients. However, not all clinical co-complications proved to be complete contraindications to exercise testing. For example, individuals that were listed for, and recovering from, lung transplants were still able to perform field tests with permission from clinicians. This shows that exercise testing still provides prognostic information when patients present with clinical complications (e.g. in the post-transplant setting) although CPET may only be deemed useful for those predicted long-term survival and accompanying treatment plans. Furthermore, patients who presented with microbiological contraindications to performing a CPET with full on-line gas analysis $(n=13)$ were still able to undertake CPET using a protocol from Werkman et al. [11], whereby peak power achieved can act as a proxy for aerobic fitness, and in adolescents with $\mathrm{CF}$, predict $\mathrm{VO}_{2 \text { peak }}$.

A further $12.3 \%$ of eligible patients refused CPET. Within this group, a number of patients refused because of the burden associated with travelling to the regional hospital where CPET takes place. However, of these travel-related refusals, half instead opted for MSWT at treatment centres nearer their home. As some patients only refused CPET because of travel, and did not refuse exercise testing itself, this suggests an acceptance of exercise testing, particularly when this is considered alongside the fact only two patients refused CPET because of a dislike of the test.

Additionally, $14.5 \%$ of eligible patients did not perform CPET for miscellaneous reasons (i.e. those that did not align with 'clinical' nor 'refusal' reasons). These include communication issues, whereby it was difficult to contact some patients, and some were no longer engaged with the CF team. Communication issues [12] have been reported previously in relation to exercise testing in cardiology, highlighting common challenges across multiple medical disciplines.

In addition, some patients were deemed too young for formal exercise testing. In the present review, five children with CF were actually under the age of 11 , and were able to complete CPET (and were thus included in the eligible $n=138$ ). The remainder of those who were excluded on the basis of age happened to be $\leq$ 11 years, and were not necessarily excluded because they were $\leq$ 11 years of age. Guidelines recommend exercise testing and prescription from 10 years of age [3], although factors such as physical stature, and cognitive ability to understand the demands of the test, will influence whether a child can, and should, perform CPET [13]. A previous observational study of CPET in clinical practice has shown that young children (7 years) were unable to perform the test due to poor cooperation [4], and therefore testing of children should be considered on a case-by-case basis, as shown by the present review.
When predicting factors associated with performing CPET, only $\mathrm{FEV}_{1}$ was statistically significant, whereby those with $\mathrm{FEV}_{1}<40 \%$ predicted were less likely to undertake CPET than individuals with $\mathrm{FEV}_{1} \geq 70 \%$ predicted. In the present cohort, only $3 / 15$ eligible patients with $\mathrm{FEV}_{1}<40 \%$ predicted performed CPET - a proportion similar to Weir et al. [4] — compared with $47 / 74$ patients with $\mathrm{FEV}_{1} \geq 70 \%$ predicted. Reasons why patients with $\mathrm{FEV}_{1}<40 \%$ predicted did not perform CPET were mainly clinical $(n=7)$, in contrast those with $\mathrm{FEV}_{1} \geq 70 \%$ predicted whereby miscellaneous reasons $(n=11)$ were predominant. Consequently, this could affect clinical practice by the occurrence of an increased number of cancelled and/or postponed tests in patients with lower lung function. Therefore, clinical teams may need to be more reactive to temporary increases in function and clinical stability in patients, so that CPET can be performed at a time when patients are healthy enough to provide a valid result.

Unlike $\mathrm{FEV}_{1}$, neither sex nor BMI was a predictor, although the latter may be biased by use of BMI categories for eligible patients aged 11-18 years, whereas BMI percentile may be more suitable [14]. Equally, given that 'obesity' was a reason given for patients not undertaking CPET, it is possible the range of body sizes observed (BMI in adults $=14.50$ $47.50 \mathrm{~kg} \mathrm{~m}^{-2}$ ) has biased this result whilst retaining a normal distribution.

Previous studies examining uptake of CPET have focused upon acute diagnostic referrals in American cardiac clinics, showing both employment and insurance status [12] influenced uptake of the test. However, previous work has focused on socio-economic factors affecting CPET, whereas the present analysis describes logistical challenges faced in implementing CPET for patients and staff alike. In some instances, patients would have been approached more than once with regard to performing the test, as the timing of first appointments may have been unfeasible for many reasons presented here (e.g. receiving antibiotic), but subsequent appointments may have been feasible (e.g. once recovered from antibiotic regimen). Therefore, the data presented in this evaluation is only related to patients who did not undertake CPET at any time and thus provides a useful insight into persistent logistical challenges faced by clinical teams in implementing CPET.

The present analysis is novel as it describes patients that (a) have a respiratory condition and (b) have chronic disease, for whom exercise testing would be considered a routine prognostic test. However, the authors acknowledge that this service evaluation is limited to a single centre and therefore application of findings to further $\mathrm{CF}$ services may be limited. For example, the geographical challenges faced by patients under the care of this rural CF centre (e.g. transport links/distance) may not exist for patients associated with urban $\mathrm{CF}$ centres, and the clinical reasons faced by other centres may differ if they have a greater number of patients, or spread of severities, under their care. Therefore, replications of such a service 
evaluation are warranted to identify common reasons for lack of uptake of CPET and allow for effective national implementation of this valuable measure.

Empowered with the understanding of the reasons for the lack of uptake with CPET, CF teams can strategically utilise this information to implement and improve services. This could include adjusting appointments to coincide with when patients are stable and healthy, coordination of services to ensure laboratory availability, and changing communication strategies to ensure patients are effectively contacted and offered the opportunity to undertake the test. Equally, there are a number of clinical cases that may not exist in following years (e.g. musculoskeletal issues, pregnancy) and therefore, uptake may be higher should these reasons be re-evaluated. Within this CF centre, there were no financial challenges faced, although this may be a future barrier for CF teams looking to implement CPET as a new service. Equipment availability has been highlighted as a barrier to undertaking in previous surveys $[6,15]$ and therefore strategies to alleviate financial pressure may be considered, such as equipment sharing with other clinical teams within hospitals (e.g. cardiology, anaesthesiology), or between hospitals and research institutions.

In conclusion, there are numerous factors that are responsible for why patients with CF do not undertake a CPET at annual review. These include clinical co-complications, refusals and miscellaneous logistical issues. Furthermore, it has been shown that patients with a $\mathrm{FEV}_{1}<40 \%_{\text {predicted }}$ are less likely to undertake CPET. Further research is warranted to identify and evaluate strategies to improve uptake of CPET for patients with $\mathrm{CF}$.

Acknowledgements The authors would like to acknowledge the assistance of Ben Bowhay, Alice Day and Sally Wilson for assistance with collation of data.

\section{Compliance with Ethical Standards}

Conflict of Interest The authors declare that there are no conflicts of interest.

Ethical Approval This was a retrospective analysis of existing, anonymised, data for purposes of service evaluation and did not therefore require ethics approval as per Health Research Authority guidelines.

Informed Consent As per the 'ethical approval' statement, as this was a retrospective analysis of existing clinical data for service evaluation, informed consent was not required.

Open Access This article is licensed under a Creative Commons Attribution 4.0 International License, which permits use, sharing, adaptation, distribution and reproduction in any medium or format, as long as you give appropriate credit to the original author(s) and the source, provide a link to the Creative Commons licence, and indicate if changes were made. The images or other third party material in this article are included in the article's Creative Commons licence, unless indicated otherwise in a credit line to the material. If material is not included in the article's Creative Commons licence and your intended use is not permitted by statutory regulation or exceeds the permitted use, you will need to obtain permission directly from the copyright holder. To view a copy of this licence, visit http://creativecommons.org/licenses/by/4.0/.

\section{References}

1. Vendrusculo FM, Heinzmann-Filho JP, da Silva JS, Perez Ruiz M, Donadio MVF. Peak oxygen uptake and mortality in cystic fibrosis: systematic review and meta-analysis. Respir Care. 2019;64(1):91-8.

2. Cystic Fibrosis Trust. Standards of care and good clinical practice for the physiotherapy management of cystic fibrosis. London, UK; 2017.

3. Hebestreit H, Arets HG, Aurora P, Boas S, Cerny F, Hulzebos EH, et al. Statement on exercise testing in cystic fibrosis. Respiration. 2015;90(4):332-51.

4. Weir E, Burns PD, Devenny A, Young D, Paton JY. Cardiopulmonary exercise testing in children with cystic fibrosis: one centre's experience. Arch Dis Child. 2017;102(5):440-4.

5. Tomlinson OW, Shelley J, Denford S, Barker AR, Oades PJ, Williams CA. Promotion of exercise in the management of cystic fibrosis - summary of national meetings. Eur J Pers Cent Healthc. 2018;6(2):196-203.

6. Stevens D, Oades PJ, Armstrong N, Williams CA. A survey of exercise testing and training in UK cystic fibrosis clinics. J Cyst Fibros. 2010;9(5):302-6.

7. WHO. Physical status: the use and interpretation of anthropometry. In: Report of a WHO Expert Consultation. Geneva: World Health Organisation; 1995.

8. Quanjer PH, Stanojevic S, Cole TJ, Baur X, Hall GL, Culver BH, et al. Multi-ethnic reference values for spirometry for the 3-95-yr age range: the global lung function 2012 equations. Eur Respir J. 2012;40(6):1324-43.

9. Singh SJ, Morgan MD, Scott S, Walters D, Hardman AE. Development of a shuttle walking test of disability in patients with chronic airways obstruction. Thorax. 1992;47(12):1019-24.

10. A. T. S. Committee on Proficiency Standards for Clinical Pulmonary Function Laboratories. ATS statement: guidelines for the six-minute walk test. Am J Respir Crit Care Med. 2002;166(1): $111-7$.

11. Werkman MS, Hulzebos EH, Helders PJ, Arets BG, Takken T. Estimating peak oxygen uptake in adolescents with cystic fibrosis. Arch Dis Child. 2014;99(1):21-5.

12. Story M, Reynolds B, Bowser M, Xu H, Lyon M. Barriers to outpatient stress testing follow-up for low-risk chest pain patients presenting to an ED chest pain unit. Am J Emerg Med. 2016;34(5): 790-3.

13. Williams CA, Saynor ZL, Tomlinson OW, Barker AR. Cystic fibrosis and physiological responses to exercise. Expert Rev Respir Med. 2014;8(6):751-62.

14. Cystic Fibrosis Trust. Nutritional management of cystic fibrosis. London, UK; 2016.

15. Sawyer A, Cavalheri V, Wood J, Hill K. Exercise testing and exercise training within cystic fibrosis centres across Australia and New Zealand: what is considered important and what is current practice? Internal Medicine Journal. 2019.

Publisher's Note Springer Nature remains neutral with regard to jurisdictional claims in published maps and institutional affiliations. 